\title{
A national analysis of risk for potential chronic kidney disease of unknown etiology in Ecuador
}

\author{
Rachel Sippy [1], Martín Lotto[2], Abigail Bideaux[3], Irene Torres[4], Sriram Narsipur[3] Ramya \\ Bhargava[3], Anna Stewart Ibarra [3] \\ 1. SUNY-Upstate Medical University, Syracuse, United States of America, University of Florida, \\ Gainesville, United States of America \\ 2. Salud Comunitaria, Machala, Ecuador \\ 3. SUNY-Upstate Medical University, Syracuse, United States of America \\ 4. Fundación Octaedro, Quito, Ecuador
}

Doi: $\underline{\text { https://doi.org/10.23936/pfr.v5i2.161 }}$

PRÁCTICA FAMILIAR RURAL | Vol.5 | No.2 | Julio 2020 | Received: 18/04/2020 | Approved: 12/07/2020

Cómo citar este artículo
Herrera, D., Gaus, D. Covid 19 evidencia. Práctica Familiar Rural. 2020 julio; 5(2).

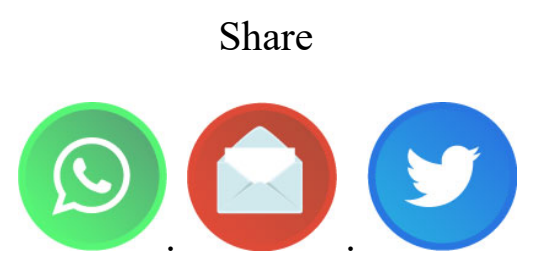

\begin{abstract}
An increase of chronic kidney disease (CKD) has affected many tropical countries but with an atypical presentation. This illness, known as Chronic Kidney Disease of Unknown Etiology $(\mathrm{CKDu})$, presents in younger adults without the typical comorbidities for CKD, often among those working in agricultural production. The cause of disease is unknown but temperature, heat stress, or dehydration are thought to contribute to the development of this condition. There is no information on whether anyone in Ecuador is affected by this illness. We describe CKD rates in Ecuador and hypothesize that CKD is impacted by temperature and the agricultural industry in Ecuador. Using publicly available data from the Instituto Nacional de Estadísticas y Censos from the years 2010 - 2015, we describe the rate of CKD among adults aged 20-45 in each province, as well as the agricultural industry across Ecuador. We combined this information with land surface temperature and used a Poisson mixed effects model to assess the relationship between mean temperature, maximum temperature and agricultural industry with CKD rates among adults aged 20-49 in each province. We found that the CKD rate is increasing in this age group over $2010-2015$ ( $\mathrm{p}=0.017$ ), and in 2015 , CKD rates were highest in Pastaza. Our spatial analysis found that both mean temperature and proportion of population in agriculture
\end{abstract}


were positively associated with CKD rate by province in 2014 and 2015. This preliminary analysis shows that temperature and agricultural industry are associated with CKD rates among adults aged $20-49$. While this association does not definitively show the presence of CKDu, it provides evidence to support further investigation of this illness in Ecuador.

Keywords: chronic kidney disease, agricultural workers, tropical zones.

\section{Un análisis nacional del riesgo de enfermedad renal crónica potencial de etiología desconocida en Ecuador}

\section{Resumen}

Un aumento de la enfermedad renal crónica (ERC) con una presentación atípica, ha afectado a muchos países tropicales. Esta enfermedad, conocida como enfermedad renal crónica de etiología desconocida $(\mathrm{CKDu})$, se presenta en adultos más jóvenes sin las comorbilidades típicas de la ERC, entre los que trabajan en la producción agrícola. Se desconoce la causa de la enfermedad, pero se cree que la temperatura, el estrés por calor o la deshidratación contribuyen al desarrollo de esta afección. En Ecuador no hay información sobre si alguien está afectado por esta enfermedad. Describimos las tasas de ERC en Ecuador e hipotetizamos que la ERC se ve afectada por la temperatura y la industria agrícola en Ecuador. Utilizando datos disponibles públicamente del Instituto Nacional de Estadísticas y Censos de los años 2010-2015, describimos la tasa de ERC entre adultos de 20 a 45 años en cada provincia, así como la industria agrícola en todo el Ecuador. Combinamos esta información con la temperatura de la superficie terrestre y utilizamos un modelo de efectos mixtos de Poisson para evaluar la relación entre la temperatura media, la temperatura máxima y la industria agrícola con tasas de ERC entre adultos de 20 a 49 años en cada provincia. Encontramos que la tasa de ERC está aumentando en este grupo de edad durante 2010-2015 ( $p=0,017)$, y en 2015, las tasas de ERC fueron más altas en Pastaza. Nuestro análisis espacial encontró que tanto la temperatura media como la proporción de la población en la agricultura se asociaron positivamente con la tasa de ERC por provincia en 2014 y 2015. Este análisis preliminar muestra que la temperatura y la industria agrícola están asociadas con las tasas de ERC entre los adultos de 20 a 49 años. Si bien esta asociación no muestra definitivamente la presencia de $\mathrm{CKDu}$, proporciona evidencia para apoyar una mayor investigación de esta enfermedad en Ecuador.

Palabras clave: enfermedad renal crónica, trabajadores agrícolas, zonas tropicales.

\section{Introducción}

Chronic Kidney Disease of Unknown Etiology (CKDu) is an emerging global health epidemic affecting lowincome agricultural workers, typically those located in tropical regions (1). It has been identified in Costa Rica, El Salvador, India, Nicaragua, Sri Lanka, and other countries (1). Depending on the population, prevalence can reach $12-25 \%$ (1-3). In regions where dialysis is unavailable, risk of death can be high. Certain occupations, including agricultural workers, fishermen, miners, or brickmakers, are at high risk for this condition (2,4-6). Clustering of cases often occurs (6), and some regions have been identified as hotspots for the disease (7-9), particularly rural communities (10).

This condition differs from typical CKD; those affected are usually young (aged 30-50) and male, without hypertension or diabetes (11), the most common precursors to CKD (12). Upon histopathological examination, interstitial fibrosis and tubular atrophy with sparing of the glomeruli are commonly observed in these patients (11). This damage is believed to be a key indicator of CKDu (13). The decline in kidney function can occur rapidly, developing within a single agricultural season (3 to 4 months) (5). 
The cause of this condition is unknown, but ongoing research suggests high temperature as a critical component. CKDu has only been observed in countries with tropical or semi-tropical climates and among working conditions involving exposure to extreme temperatures. Other hypotheses include dehydration, infection, pesticide exposure, heavy metals, water contamination, or use of certain medications (14), or some combination of the factors. Genetic or developmental factors may also play a role (15), as family history of CKD is also important (12).

Comprehensive studies are lacking from many countries where CKDu is suspected, such as Ecuador. In this exploratory analysis, we describe CKD rates in Ecuador and assess ecological associations between agricultural systems, temperature, and CKD among working-age populations (approximately 20-45 years old) in Ecuador. We hypothesize that CKD in working-age adults is associated with temperature and agricultural production.

\section{Methods}

We analyzed publicly available data for Ecuador containing morbidity records of hospitalized individuals from 2010 - 2015 by province ( $\mathrm{n}=23$, Galápagos excluded), from El Registro Estadístico de Camas y Egresos Hospitalarios (Instituto Nacional de Estadísticas y Censos (INEC), https://www.ecuadorencifras.gob.ec/camas-y-egresos-hospitalarios/). Province-level records for chronic kidney disease (CKD) (N18, 10th International Classification of Disease) in young to middle-aged adults (ages 20-45) were matched to age-specific province population projections from 2010-2015 national census data to calculate CKD rates (INEC, https://www.ecuadorencifras.gob.ec/poblacion-y-migracion/) for each province as well as a national CKD rate. A test for trend was used to assess the change in rate over the time period. We used la Encuesta de Superficie y Producción Agropecuaria Continua (2012-2015) to calculate the proportion of each province's population involved in agriculture (including paid or unpaid agricultural labor and full or part-time employment). The mean and maximum annual temperature in each province was calculated using data from the 8-day, 1-km Land Surface Temperature/Emissivity (MOD11A1.006) product (16) from the Terra MOderate Resolution Imaging Spectroradiometer satellite, accessed using the Application for Extracting and Exploring Analysis Ready Samples (AppEEARS) (17). Using Poisson mixed effects models (province and year as random effects), we assessed the relationship between agricultural employment (proportion employed), average temperature, and CKD rates for 20122015. Agricultural employment, mean temperature and maximum temperature were scaled and a population offset was applied (population aged 20-49). Bootstrapping (1000 replicates) was used to estimate 95\% confidence intervals for each effect estimate. Residuals were examined for remaining spatial autocorrelation using global Moran's I. Model fit was assessed using Aikake's Information Criterion (AIC). Data were cleaned and analyzed using R version 3.4.1 (R Foundation for Statistical Computing, Vienna, Austria) and RStudio (RStudio Incorporated, Boston, USA).

\section{Results}

\section{CKD and Agriculture Descriptive Analysis}

Over 2010-2015, we found an increasing trend in the CKD rate in males aged 20-45 ( $\mathrm{p}=0.017)$, Figure 1. The number of workers in agriculture is stable in Ecuador, with 2,019,801-2,292,795 employed each year, including those informally employed (unpaid family or friends) or employed seasonally (Figure 1). The spatial distribution of agricultural workers is in Figure 2. Bolívar had the highest population proportion involved in agriculture in 2012 (39.6\%) and 2015 (33.9\%). In 2013, the highest proportion was in Cotopaxi $(32.3 \%)$. Carchi had the highest proportion in 2013 (50.3\%). The spatial distribution of CKD among adults aged 20-49 are in Figure 3. From 2010-2012, the highest rates of CKD among young people were observed in Tungurahua (26.6 per 100,000 in 2010, 22.5 per 100,000 in 2011, and 22.6 per 100,000 in 2012). In 2013, the highest rate was in Santa Elena (30.0 per 100,000 people). In 2014, the highest rate was in Imbabura (33.7 100,000 people). In 2015 the highest rate was in Pastaza (42.8 per 100,000 people). 
Figure 1: Prevalence of CKD and Agricultural Activity in Ecuador, 2010-2015

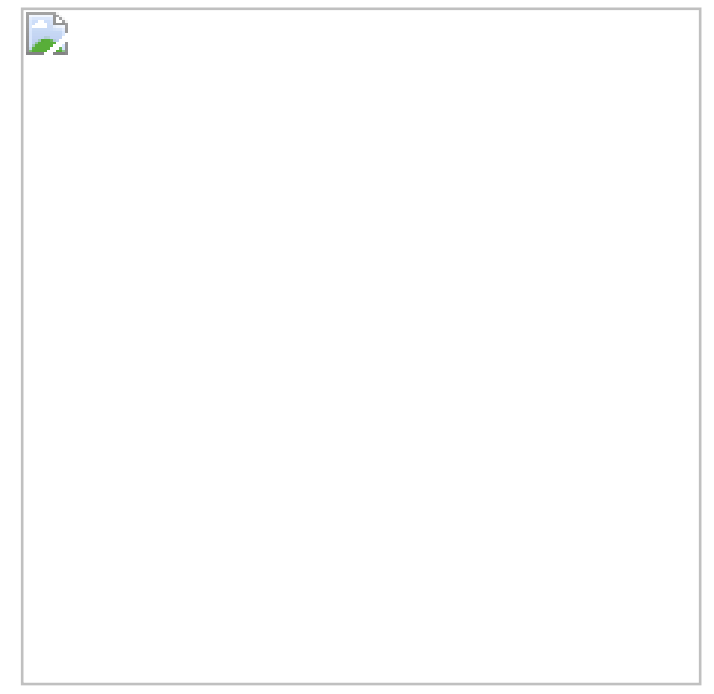

The rate of CKD diagnosis among ages 20-45 is given for the years 2010-2015 (a). The number of males (green) and females (blue) employed in agricultural activity is also given for these years (b).

Figure 2: Proportion of Population Employed in Agriculture, 2012-2015

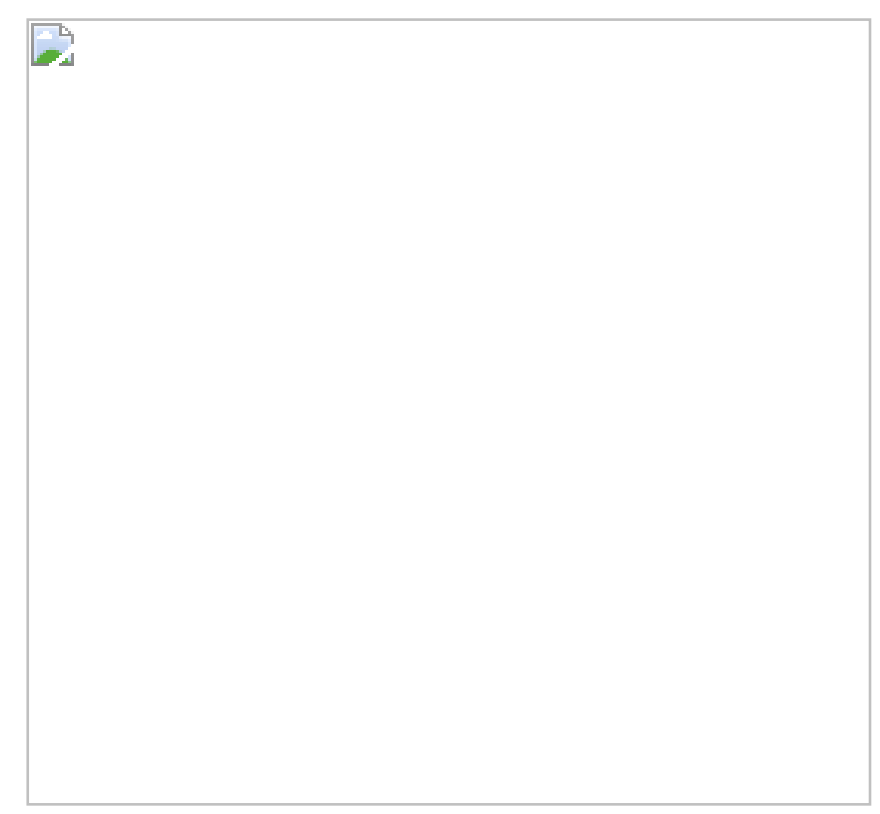

For each province, the proportion of the total population employed in agriculture is given for $2012-2015$. This includes full or part-time employment and paid or unpaid agricultural labor.

Figure 3: CKD Rate by Province, Ages 20-49, 2010-2015 


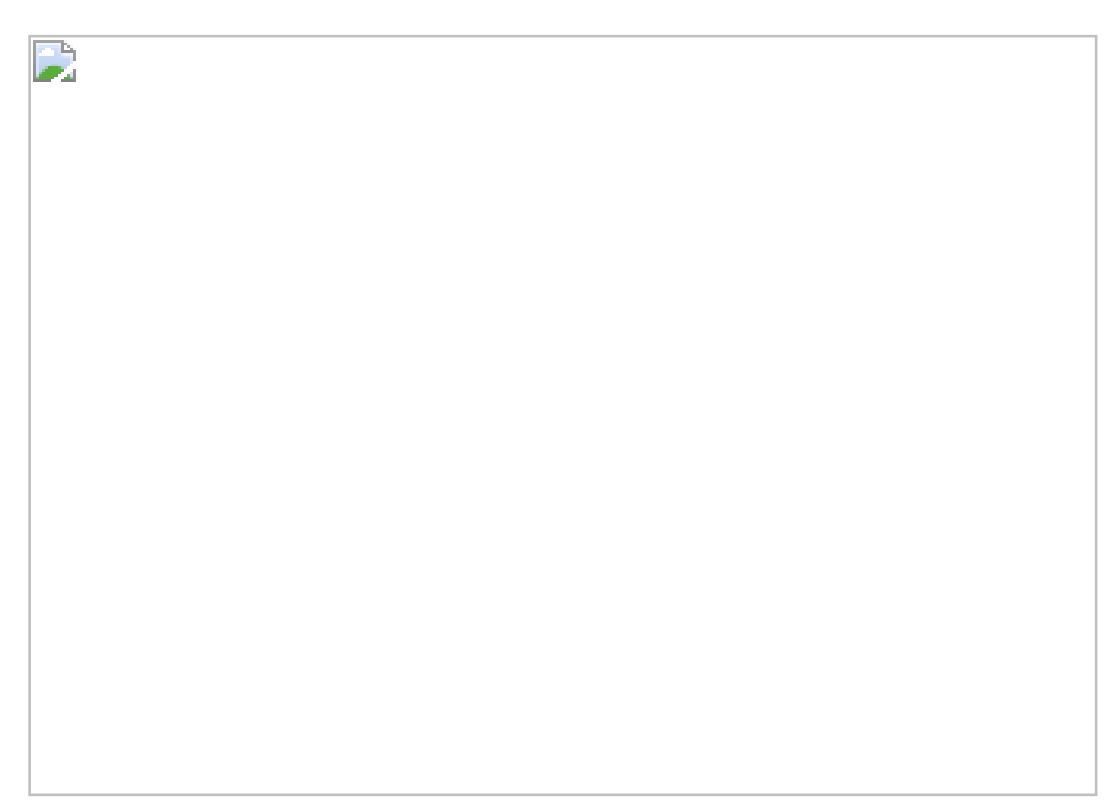

For each province, the CKD rate (per 100,000) for adults aged 20-49 is given for the years 2010-2015. Ecological Analysis

Analyses of 2012 - 2015 found negative relationships between agricultural proportion and mean temperature and CKD rates, and a positive relationship between maximum temperature and CKD rates. The Moran's I test found no remaining spatial autocorrelation in the model. On average, a 10\% increase in the agricultural proportion would lead to a $9 \%$ decrease in the number of CKD cases per 100,000 people aged $20-49$ per year. On average, a mean temperature increase of $5^{\circ}$ Celsius would lead to a $13 \%$ decrease in the CKD rate, and a maximum temperature increase of $5^{\circ}$ Celsius would lead to a $7 \%$ increase in the CKD rate.

Table 1. Effect Estimates for Ecological Analysis

\begin{tabular}{|l|l|l|l|c|}
\hline \multicolumn{5}{|l|}{$\begin{array}{l}\text { Effect estimates and p-values from the model are given with 95\% } \\
\text { confidence intervals as calculated from a bootstrapping procedure. }\end{array}$} \\
\hline Variable & Effect & \multicolumn{2}{|c|}{$95 \%$ CI } & p-value \\
\hline Proportion in Agriculture (10\%) & 0.91 & 0.76 & 1.09 & 0.021 \\
\hline Mean Temperature $\left(5^{\circ} \mathrm{C}\right)$ & 0.87 & 0.59 & 1.13 & 0.081 \\
\hline Maximum Temperature (5 $\mathrm{C})$ & 1.07 & 0.85 & 1.31 & 0.159 \\
\hline $95 \% \mathrm{CI}=95 \%$ confidence interval, C=Celsius &
\end{tabular}

\section{Discussion}

CKDu is an important burden in multiple tropical countries. In this analysis, we assessed the burden of CKD among adults aged 20-49 and hypothesized that $\mathrm{CKD}$ in this age group is influenced by the agricultural 
industry and temperature. Working in high temperature environments can cause heat stress and dehydration, acute kidney damage is observed in workers in these conditions, in addition to physiological signs of CKD progression (18). Positive associations between temperature and CKDu have been found in Central America, and results from studies of heat stress have been mixed, depending on location (positive association in Central America, positive and negative in Southeast Asia) (1). In our results, we found that mean temperature had a negative association while maximum temperature had a positive association with CKDu rates. Temperature alone does not seem to be the driver of the CKDu epidemic: there are hot regions where $\mathrm{CKDu}$ has not been reported (though this may be due to lack of surveillance) and not all workers in hot regions seem to be affected by CKDu, even where other workers are affected (18). We found a negative association between the proportion of the population working in agriculture and the CKD rate among adults aged $20-49$. This may be due to the limitations of ecological analyses: we do not know if the observed CKD is in agricultural workers or not so the true relationship between CKD and agriculture in Ecuador may not be fully reflected in this analysis. Additional information on specific agricultural practices in Ecuador will be needed to understand this association.

For those in working in agriculture, exposure to pesticides and other agrochemicals are an important consideration. These chemicals are used to control weeds, insects, and other pests in the production of food or other agricultural products. Application of these products or working among crops sprayed with agrochemicals may result in significant exposure to agricultural workers. Research in Sri Lanka and Central America has shown positive associations between agrochemical use and CKDs (14). Agrochemicals may have a combined effect with temperature: damage from heat stress may leave the kidneys more vulnerable to the effects of agrochemicals. Data on agrochemical use were unavailable for the present study.

Heavy metals are another important area of research. Metals such as cadmium, lead, chromium have been reported at elevated levels among people living in CKDu hotspots (19). These heavy metals are known to cause patterns of damage similar to that of CKDu (20). Food is believed to be the primary source of exposure for heavy metals (21). Research of the effect of heavy metals on CKDu have found mixed results (1).

Agriculture is an important industry in Ecuador: in 2015 more than 2.7 million hectares of land were being used for permanent or annual crops (22). Top exports for Ecuador include bananas, cacao, and flowers. These crops require the use of pesticides and agrochemicals and surveys in Ecuador indicate that pesticides are widely used and agrochemicals are a major occupational exposure for agricultural workers in Ecuador (23). In 2015 , only $22 \%$ of agricultural workers had been trained in proper use of agrochemicals and only $28 \%$ reported reading the labels on the agrochemical products they use (22). Agrochemicals can easily contaminate local waterways, as has been demonstrated in Guayas River watershed (24); persistent agrochemicals allow for additional exposure among the general population. Contaminated water (with pesticides or heavy metals) as a cause for CKDu is an additional hypothesis under study (1).

\section{Limitations}

This initial analysis is likely confounded by additional variables such as crop type, agrochemical use, and poverty levels. These associations are ecological; we do not have information on the rates of CKD among agricultural workers and do not know the true burden of disease among this population in Ecuador. In addition, the data on CKD are from the general population, not the employed population, meaning the rate estimate is likely biased. In addition, El Registro Estadístico de Camas y Egresos Hospitalarios does not include all CKD cases in Ecuador, only those that had a hospital visit related to CKD within a given year, meaning these rates are underestimates. This ecological analysis is the first examination of potential CKDu in Ecuador. It is critical to conduct more detailed epidemiologic research to understand if CKDu is affecting vulnerable populations in Ecuador.

\section{Conclusions}


$\mathrm{CKDu}$ is a serious condition that can lead to death or severe impairment if dialysis is unavailable. It mostly affects occupational groups, with agricultural workers often developing the disease within a single crop season. Clusters of CKDu have appeared in many tropical and subtropical countries. We found that CKD among adults aged 20-49 years was associated with temperature and agricultural industry in Ecuador, but that some of the associations were in unexpected directions, likely due to unmeasured confounding. In order to determine if $\mathrm{CKDu}$ is affecting agricultural workers or other populations in Ecuador, it is necessary to conduct more detailed epidemiologic research.

\section{References}

1. Lunyera J, Mohottige D, Isenburg MV, Jeuland M, Patel UD, Stanifer JW. CKD of Uncertain Etiology: A Systematic Review. Clin J Am Soc Nephrol CJASN. 2016 Mar 7;11(3):379-85.

2. Gallo-Ruiz L, Sennett CM, Sanchez-Delgado M, Garcia-Urbina A, Gamez-Altamirano T, Basra K, et al. Prevalence and Risk Factors for CKD Among Brickmaking Workers in La Paz Centro, Nicaragua. Am J Kidney Dis Off J Natl Kidney Found. 2019 Feb 27;

3. Tatapudi RR, Rentala S, Gullipalli P, Komarraju AL, Singh AK, Tatapudi VS, et al. High Prevalence of CKD of Unknown Etiology in Uddanam, India. Kidney Int Rep. 2019 Mar;4(3):380-9.

4. Riefkohl A, Ramírez-Rubio O, Laws RL, McClean MD, Weiner DE, Kaufman JS, et al. Leptospira seropositivity as a risk factor for Mesoamerican Nephropathy. Int J Occup Environ Health. 2017 Jan;23(1):1-10.

5. Sorensen CJ, Butler-Dawson J, Dally M, Krisher L, Griffin BR, Johnson RJ, et al. Risk Factors and Mechanisms Underlying Cross-Shift Decline in Kidney Function in Guatemalan Sugarcane Workers. J Occup Environ Med. 2019 Mar;61(3):239-50.

6. Ranasinghe AV, Kumara GWGP, Karunarathna RH, De Silva AP, Sachintani KGD, Gunawardena JMC, et al. The incidence, prevalence and trends of Chronic Kidney Disease and Chronic Kidney Disease of uncertain aetiology $(\mathrm{CKDu})$ in the North Central Province of Sri Lanka: an analysis of 30,566 patients. BMC Nephrol. 2019 Dec;20(1):338.

7. Abraham G, Agarwal SK, Gowrishankar S, Vijayan M. Chronic Kidney Disease of Unknown Etiology: Hotspots in India and Other Asian Countries. Semin Nephrol. 2019 May;39(3):272-7.

8. Aguilar DJ, Madero M. Other Potential CKD Hotspots in the World: The Cases of Mexico and the United States. Semin Nephrol. 2019 May;39(3):300-7.

9. Obrador GT, Levin A. CKD Hotspots: Challenges and Areas of Opportunity. Semin Nephrol. 2019 May;39(3):308-14.

10. Caplin B, Yang C-W, Anand S, Levin A, Madero M, Saran R, et al. The International Society of Nephrology's International Consortium of Collaborators on Chronic Kidney Disease of Unknown Etiology: report of the working group on approaches to population-level detection strategies and recommendations for a minimum dataset. Kidney Int. 2019 Jan;95(1):4-10.

11. Fischer RSB, Vangala C, Truong L, Mandayam S, Chavarria D, Llanes OMG, et al. Early detection of acute tubulointerstitial nephritis in the genesis of Mesoamerican nephropathy. Kidney Int. 2018 Mar 1;93(3):681-90.

12. Lea JP, Nicholas SB. Diabetes mellitus and hypertension: key risk factors for kidney disease. J Natl Med Assoc. 2002 Aug;94(8 Suppl):7S-15S.

13. Nanayakkara S, Komiya T, Ratnatunga N, Senevirathna STMLD, Harada KH, Hitomi $T$, et al. Tubulointerstitial damage as the major pathological lesion in endemic chronic kidney disease among farmers in North Central Province of Sri Lanka. Environ Health Prev Med. 2012 May;17(3):213-21.

14. Pearce N, Caplin B. Let's take the heat out of the CKDu debate: more evidence is needed. Occup Environ Med. 2019 Jun;76(6):357-9.

15. Friedman D, Luyckx VA. Genetic and Developmental Factors in Chronic Kidney Disease Hotspots. Semin Nephrol. 2019 May;39(3):244-55.

16. Wan Z, Hook S, Hulley G. MOD11A2 MODIS/Terra Land Surface Temperature and the Emissivity 8Day L3 Global 1km SIN Grid. DAAC NL, editor. 2015.

17. AppEEARS Team. Application for Extracting and Exploring Analysis Ready Samples (AppEEARS). [Internet]. Sioux Falls, SD: NASA EOSDIS Land Processes Distributed Active Archive Center (LP DAAC); 
2020. Available from: https://lpdaacsvc.cr.usgs.gov/appeears

18. Herath C, Jayasumana C, De Silva PMCS, De Silva PHC, Siribaddana S, De Broe ME. Kidney Diseases in Agricultural Communities: A Case Against Heat-Stress Nephropathy. Kidney Int Rep. 2017 Oct 24;3(2):271-80.

19. Kulathunga MRDL, Ayanka Wijayawardena MA, Naidu R, Wijeratne AW. Chronic kidney disease of unknown aetiology in Sri Lanka and the exposure to environmental chemicals: a review of literature. Environ Geochem Health. 2019 Feb 27;

20. Barbier O, Jacquillet G, Tauc M, Cougnon M, Poujeol P. Effect of heavy metals on, and handling by, the kidney. Nephron Physiol. 2005;99(4):p105-110.

21. Ananda Jayalal TB, Jayaruwan Bandara TWMA, Mahawithanage STC, Wansapala MAJ, Galappaththi SPL. A quantitative analysis of chronic exposure of selected heavy metals in a model diet in a CKD hotspot in Sri Lanka. BMC Nephrol. 2019 Jun 7;20(1):208.

22. INEC. Información Ambiental en la Agricultura 2015 [Internet]. Instituto Nacional de Estadística y censos; 2015. Available from: https://www.ecuadorencifras.gob.ec/encuesta-de-superficie-y-produccionagropecuaria-continua-2015-2016-2017-2/

23. Hurtig AK, San Sebastián M, Soto A, Shingre A, Zambrano D, Guerrero W. Pesticide use among farmers in the Amazon basin of Ecuador. Arch Environ Health. 2003 Apr;58(4):223-8.

24. Deknock A, De Troyer N, Houbraken M, Dominguez-Granda L, Nolivos I, Van Echelpoel W, et al. Distribution of agricultural pesticides in the freshwater environment of the Guayas river basin (Ecuador). Sci Total Environ. 2019 Jan 1;646:996-1008. 